\title{
PENGEMBANGAN MULTIMEDIA PEMBELAJARAN PPKn KELAS VIII SEKOLAH MENENGAH PERTAMA
}

\author{
Sr. Marcella Sumarsih, LR Retno Susanti, Adeng Slamet \\ Program Magister Teknologi Pendidikan, Fakultas Ilmu Pendidikan, Universitas Negeri Sriwijaya \\ Jalan Srijaya Negara Bukit Besar Palembang, Sumatera Selatan, Kode Pos 30128, Indonesia \\ sr.marcella.hk01@gmail.com
}

\section{Article History}

Received: 26 Mei 2021, Accepted: 01 September 2021, Published: 20 November 2021

\begin{abstract}
Abstrak
Pengembangan yang bertujuan menghasilkan software multimedia yang valid, praktis, dan efektif terhadap hasil belajar peserta didik. Penelitian dilaksanakan di SMP Xaverius 6 Palembang. Penelitian ini menggunakan jenis penelitian pengembangan dengan model pengambangan Hannafin \& Peck yang telah dimodifikasi. Terdapat tiga tahapan dalam model pengembangan Hannafin \& Peck yaitu analisis kebutuhan, desain, serta pengembangan dan implementasi, dan setiap tahapnya disertai dengan evaluasi dan revisi. Multimedia yang dikembangkan dilakukan pengujian oleh ahli untuk mendapatkan hasil validas terhadap materi, desain, dan media. Validasi multimedia pembelajaran oleh ahli desain pembelajaran, ahli materi dan ahli media dengan hasil rata-rata 84,20\% terkategori sangat valid. Multimedia pembelajaran PPKn dinyatakan praktis setelah dilakukan evaluasi formatif kedua dengan rerata $82,52 \%$ dengan kategori sangat praktis. Dilihat dari 90,6\% peserta didik dapat mencapai KKM dengan nilai rerata N-gain yaitu 0,56 dengan kriteria sedang Multimedia pembelajaran PPKn dinyatakan efektif terhadap hasil belajar peserta didik kelas VIII di SMP Xaverius 6 Palembang. Kesimpulan bahwa multimedia pembelajaran PPKn dengan aplikasi Canva valid, praktis, dan efektif terhadap hasil belajar peserta didik.
\end{abstract}

Keyword: Pengembangan, Multimedia Pembelajaran, PPKn

\begin{abstract}
This study aims to produce valid, practical, and effective multimedia on student learning outcomes. The research was conducted at Xaverius 6 Junior High School Palembang. This study uses a type of development research with a modified Hannafin \& Peck floating model. There are three stages in the Hannafin \& Peck development model, namely needs analysis, design, and development and implementation, and each stage is accompanied by evaluation and revision. The developed multimedia is trial by experts to get the results of the validity of the material, design, and media. The validity of the learning media was assessed by learning design experts, material experts and media experts with an average result of $84.20 \%$ with a very valid category. PPKn learning multimedia was declared practical after the second formative evaluation was carried out with an average of $82.52 \%$ in the very practical category. Judging from $90.6 \%$ of students can reach the KKM with an average $N$ gain value of 0.56 with the criteria being that Multimedia Civics learning is declared effective on the learning outcomes of class VIII students at SMP Xaverius 6 Palembang. The conclusion is that the multimedia learning of Civics with the Canva application is valid, practical, and effective on student learning outcomes.
\end{abstract}

Keyword: Development, Learning Multimedia, Education of the Pancasila and Citizenship 


\section{PENDAHULUAN}

Bidang studi Pendidikan Pancasila dan Kewarganegaraan (PPKn) pada kurikulum 2013 semula dikenal dengan bidang studi Pendidikan Kewarganegaraan (PKn) dalam kurikulum 2006 yang telah diperbaiki (Nurhidayah dkk, 2020). Perbaikan PKn menjadi PPKn dilakukan bertumpu dari peninjauan (1) Pancasila sebagai dasar negara dan pandangan hidup bangsa difungsikan dan digunakan kan sebagai subtansi yang menjadi sumber acuan dan kriteria keberhasilan pencapaian tingkat kompetensi dan pengelolaan dari semua ranah bidang studi Pendidikan Pancasila dan Kewarganegaraan; (2) subtansi dan roh Undang-Undang Dasar Republik Indonesia tahun 1945, nilai dan semangat Bhinneka Tunggal Ika dan tanggung jawab Negara Kesatuan Republik Indonesia diposisikan pada ranah menyatu dari Pendidikan Pancasila dan Kewarganegaraan, yang sebagai media penyusunan psikologis-paedagogis pembentukan warganegara Indonsia yang berkebribadian Pancasila (Khasana dkk, 2018). Pada tingkat SD/MI, SMP/MTs, SMA/SMK/MA, PPKn bidang studi yang diwajibkan dan diplaningkan untuk melahirkan peserta didik yang mempunyai keimanan dan akhlak mulia sebagai halnya diarahkan oleh falsafah hidup bangsa Indonesia, yaitu Pancasila sehingga bisa berfungsi sebagai warga negara yang efektif dan bertanggung jawab (Wahono \& Wardhani, 2016)

Gagasan dan harapan yang terkandung dalam Pendidikan Pancasila dan Kewarganegaraan dapat berkontribusi dan memberikan solusi atas berbagai krisis yang melanda Indonesia, khususnya krisis multidimensi (Marlina, 2019). Kemiskinan, pengangguran, aktivisme, pembangunan yang tidak seimbang, kekacauan tata kota, kejahatan, korupsi, kerusakan lingkungan, narkoba, ketimpangan pendidikan merupakan krisis multidimensi di Indonesia. Oleh karena itu, misi kewarganegaraan sebagai mata pelajaran adalah membudayakan peradaban. Pancasila berharap menjadikan peserta didik beradab dan memberdayakan mereka menjadi warga negara yang cerdas, baik dan bertanggung jawab. (Nugroho, 2020; Sari \& Wati, 2020).

Dalam proses pelaksanaannya, pembelajaran PPKn harus didukung oleh pendidik yang mumpuni dan mampu menguasai metode pembelajaran yang efektif untuk menunjang keberhasilan pembelajaran (Riastuti dkk, 2018). Pendidik seharusnya mampu menyediakan pembelajaran secara kreatif dan inovatif (Widyaningrum, 2016). Namun pada kenyataannya selama ini pembelajaran PKn sering dianggap membosankan oleh sebagian besar siswa, karena pendidik PKn selama ini menggunakan metode pembelajaran yang lama yaitu ceramah dan teori, serta model dan media pembelajaran yang mereka gunakan kurang kreatif dan tampilannya kurang menarik (Widiatmaka, 2016). Dalam hal ini penggunaan metode pembelajaran sangatlah berpengaruh dalam tercapainya hasil akhir yang baik.

Untuk mencapai tujuan dan indikator tersebut, dalam pelaksanaan pembelajaran, alat, bahan, dan sumber belajar perlu diatur agar dapat dilihat oleh siswa dan mudah digunakan (Wati, 2010). Macam sumber belajar yaitu model, media cetak, gambar-gambar, kliping dan laporan (Muhson, 2010). Media pembelajaran dalam PPKn harus dapat menstimulus lahirnya pembelajaran yang aktif dan kreaktif (Bagaskoro, 2019). Berkaitan pernyataan sebelumnya, maka berbagai jenis media pembelajaran seperti media visual, media audio video atau media berbasis komputer dapat dimanfaatkan untuk pembelajaran PPKn. Media pembelajaran ialah suatu komponen utama yang terkandung dalam proses pembelajaran, maka media pembelajaran haruslah mendapat perhatian lebih dari seorang pendidik (Junaidi, 2019). Namun yang terjadi, dalam implementasi media pembelajaran selama ini tidak optimal dan belum bervariasi yang menjadi salah satu penyebab kurang minatnya peserta didik dalam belajar PPKn (Nurrita, 2018). Hal ini begitu disayangkan, karena bertentangan dengan tujuan media pembelajaran, yaitu sebagai media bantu pembelajran yang berguna untuk memperlancar proses pembelajaran. Pendidik PPKn dalam menyusun perencanaan pembelajaran, mengacu pada silabus, buku teks pelajaran, dan buku panduan pendidik, dengan memperhatikan prinsip-prinsip penyusunan dan langkah-langkahnya penyusunan RPP (Wildan, 2017). Pendidik menjalankan proses Pendidikan 
serta evaluasi sesuai RPP untuk membuat peningkatan efektifitas dan efisiensi ketercapaian kompetensi lulusan (Barrimi dkk, 2013).

Berdasarkan hasil observasi lapangan dari pelaksanaan pembelajaran PPKn sebagian besar peserta didik tidak dapat melampaui Kriteria Ketuntasan Minimal (KKM), KKM untuk mata pelajaran PPKn di SMP Xaverius 6 Palembang yaitu 70, peserta didik yang hasil belajarnya dapat melampaui KKM 24 anak atau $30 \%$ dari jumlah peserta didik kelas 8 Berdasarkan laporan pendidik dan wawancara yang dilakukan dengan 12 peserta didik mengenai pembelajaran PPKn, peserta didik ternyata membutuhkan media pembelajaran yang dirancang dengan baik, dari 32 peserta didik 28 diantaranya menyukai media pembelajaran audio dan visual.

Teknologi diharapkan mampu dijadikan salah satu cara untuk memajukan Pendidikan di Indonesia (Aprianto, Ulfa, dan Husna, 2021). Pada tulisan penelitian ini digunakan teknologi Pendidikan berupa media pembelajaran berbasis aplikasi canva. Aplikasi ini mempunyai kelebihan untuk memaparkan materi, canva mudah dalam pengoperasian. Selanjutnya aplikasi canva merupakan sarana yang mampu mempermudah presentasi, dikarenakan aplikasi ini dapat menampilkan teks, animasi, video, audio, gambar, grafik dan lain-lain berdasarkan tampilan yang diinginkan serta mampu menjadikan peserta didik untuk fokus memperhatikan pelajaran karena tampilannya yang menarik. Namun demikan penggunaan canva belum terlaksanakan oleh para pendidik di sekolah yang diteliti. Penggunaan canva dimaksudkan agar mampu menjadi solusi masalah belajar peserta didik (Pravasta dkk, 2018).

Penelitian yang relevan dengan pengembangan media pembelajaran telah banyak menunjukan keberhasilan, maka butuh dilaksanakan penelitian lanjutan berdasarkan rekomendasi penelitian terdahulu. Pengembangan multimedia linier oleh Reni Anita (2019) pada mata pelajaran PPKn menggunakan aplikasi movie maker untuk kelas X SMA menghasilkan produk yang valid, praktis dan efektif. Penelitian lainya adalah Agustini \& Purnomo (2020) pengembangan multimedia interaktif tenun polos memiliki efektivitas terhadap peningkatan kompetensi peserta didik yang terlihat dari prestasi belajar. Penelitian lain dilakukan oleh Tanjung \& Faiza (2019), penerapan media pembelajaran canva dinyatakan valid dan praktis untuk diterapkan pada kelas eksperimen. Media canva juga dapat diimplementasikan pada mata pelajaran lain. Selanjutnya penelitian terkait aplikasi canva yaitu Wicaksana dkk., (2020) mengenai Pengembangan Poster Kesehatan Reproduksi Berbasis Pendidikan Karakter Menggunakan canva pada Usia Remaja, hasil dari penelitian tersebut ialah didapati nilai siswa-siswi meningkat saat penggunaan media poster sehingga poster sudah efektif digunakan saat kegiatan pembelajaran.

Berdasarkan pemaparan diatas serta didukung oleh analisis kebutuhan dan penelitian terdahulu, maka telah dilaksanakan penelitian pengembangan multimedia pembelajaran PPKn Kelas VIII Sekolah Menengah Pertama. Pembelajaran Pendidikan Pancasila dan Kewarganegaraan yang akan diteliti selama ini mayoritas peserta didik tidak bisa melampui KKM.:

\section{METODE}

Jenis penelitian pengembangan (Research \& Development) digunakan pada penelitian ini, dengan model pengembangan Hannafin dan Peck, dimana model pengembangan ini berorientasi pada hasil (produk), bukan untuk menguji teori. Penelitian dilakukan di Sekolah Menengah Pertama (SMP) Xaverius 6 Palembang, Subjek penelitianya adalah peserta didik kelas VIII.Pada media pembelajaran PPKn menggunakan aplikasi Canva di Sekolah Menengah Pertama. pengembangan model Hannafin dan Peck terdiri dari tiga tahap yaitu analisis kebutuhan, desain, serta pengembangan dan implementasi. Adapun prosedur penelitian ini menirukan langkah-langkah pada model sebagai berikut analisis kebutuhan, desain pengembangan dan implementasi. 
Penggunaan instrumen untuk pengumpulan data dalam penelitian pengembangan ini yaitu lembar observasi, lembar validasi terhadap materi, media dan desain pembelajaran, angket dan soal tes pilihan ganda. Lembar pengamatan digunakan untuk mengetahui keaktifan pebelajar, dalam proses pembelajaran, lembar validasi untuk menangkap repson ahli dalam validasi produk. Prosedur Penelitian ini menggunakan model pembelajaran Hannafin dan Peck, dimana model pengembangan ini berorientasi pada hasil (produk). Pada media pembelajaran PPKn menggunakan aplikasi Canva di Sekolah Menengah Pertama.

Data tes dilakukan Analisis dengan membandingkan antara presentase hasil ketuntasan pretest dan hasil ketuntasan posttest, kemudian data hasil belajar peserta didik ini dianalisis untuk mengetahui kriteria hasil belajar peserta didik. Analisis data hasil tes dilakukan dengan melihat nilai hasil belajar peserta didik dengan mengacu pada nilai KKM (Kriteria Ketuntasan Minimal). Kriteria Ketuntasan Minimal (KKM) untuk mata pelajaran PPKn di SMP Xaverius 6 Palembang yaitu 70. Selain dengan meggunakan KKM individu, data hasil tes dianalisis menggunakan KKM klasikal. Multimedia pembelajaran PPKn dikatakan efektif apabila 85\% peserta didik dapat mencapai atau melebihi KKM.

Untuk melihat peningkatan dan perbandingan rerata nilai yang diperoleh peserta didik pada saat pretest menggunakan perhitungan Ngain. Keefektifan media Canva ditinjau berdasarkan perbandingan nilai gain yang dinormalisasi, dapat dihitung dengan menggunakan persamaan. G merupakan gain yang dinormalisasi dari kedua model. merupakan skor maksimum dari pretest dan posttest. merupakan skor tes akhir, sedangkan adalah skor tes awal. Perolehan $\mathrm{N}$ gain skor dapat diklasifikasikan sebagai berikut (1) Jika $\mathrm{g} \geq 0,7$, maka yang nilainya termasuk dalam kategori tinggi; (2) Jika $0,3 \leq \mathrm{g} \leq 0,7$, maka yang nilainya termasuk dalam kategori sedang; dan (3) Jika $\mathrm{g}<0,7$, maka yang nilainya termasuk dalam kategori rendah (Hake, 1999).

\section{HASIL}

Tahap awal pada penelitian ini adalah melakukan analisis kebutuhan siswa dengan melakukan observasi dan wawancara pada pendidik dan siswa di SMP Xaverius 6 Palembang. Setelah mengetahui permasalahan belajar yang terjadi pada SMP Xaverius 6 Palembang, didapatkan kesimpulan bahwa perlu adanya media pembelajaran berupa multimedia berbasis canva yang dapat menyelesaikan permasalahan belajar PPKn di SMP Xaverius 6 Palembang. Selanjutnya pada tahapan desain dan pengembangan digunakan aplikasi Canva untuk membangun multimedia ini. Pada aplikasi canva terdapat banyak fitur yang dapat mempermudah pembelajaran seperti video, gambar, audio, dan animasi. Setelah selesai pengembangan media dilaksanakan validasi ahli media, ahli desain dan ahli materi. Tujuan dilaksanakan validasi ini adalah agar mendapatkan dan mengetahui kevalidan dan kelayakan multimedia berbasis canva pada mata pelajaran PPKn. Setelah proses validasi, langkah berikutnya uji coba produk oleh siswa untuk memperoleh tanggapan. Berdasarkan hasil validasi dan uji coba yang telah dilakukan kepada satu ahli media, satu ahli materi, dan beberapa siswa SMP Xaverius 6 Palembang diperoleh kesimpulan bahwa multimedia berbasis canva pada mata pelajaran PPKn valid dan layak untuk digunakan.

Agar menghasilkan produk multimedia berbasis aplikasi Canva yang valid, maka setelah multimedia selesai dibuat berikutnya dilakukan pengujian terhadap materi, desain, dan media. Validasi dilakukan oleh ahli desain pembelajaran, ahli materi, dan ahli media berdasarkan indikator yang telah tersedia., Aspek- aspek yang dinilai oleh ahli desain pembelajaran dan materi mencakup kelayakan isi, kelayakan penyajian, dan bahasa. Sedangkan aspek yang dinilai oleh ahli media meliputi kegrafisan, pewarnaan, keinteraktifan dan suara.

Analisis penilaian validator di lakukan setelah analisis komentar dan saran dari lembar validasi oleh validator. Analisis penilaian validator untuk mengetahui tingkat kevalidan multimedia pembelajaran PPKn yang sedang dikembangkan. Hasil rekapitulasi perhitungan lembar observasi oleh ahli dipaparkan pada tabel 1 dibawah ini. 
Tabel 1. Rekapitulasi Hasil Tahap Expert Review

\begin{tabular}{lllll}
\hline No. & Aspek & $\begin{array}{l}\text { Validator } \\
(\text { Expert })\end{array}$ & Skor & Kategori \\
\hline 1 & Media & HS & 83,64 & Sangat Valid \\
2 & Desain Pembelajaran & HD & 80 & Valid \\
3 & Materi & SP & 88,96 & Sangat Valid \\
\hline Rerata & & $\mathbf{8 4 , 2 0}$ & Sangat Valid \\
\hline
\end{tabular}

Tahapan evaluasi formatif dilaksanakan sesudah tahap pengujian materi, desain, dan media, bertujuan mengetahui kelemahan multimedia pembelajaran yang telah di desain dan telah dinilai oleh para ahli berdasarkan pandangan peserta didik, kelas VIII SMP Xaverius 6 Palembang. Tahap evaluasi formatif dilaksanakan uji coba kepada sepuluh peserta didik yang kemampuan beragam ada yang tinggi, sedang dan rendah, selanjutnya dari beragam kategori yaitu jenis kelamin, kondisi sosial ekonomi, agama, dan suku. Selain untuk mengenali kelemahan evaluasi formatif tahap kedua ini bertujuan untuk melihat kepraktisan produk sebelum uji coba lapangan, dengan melakukan proses pembelajaran kepada peserta didik menggunakan multimedia pembelajaran PPKn yang sedang dikembangkan. Pada akhir proses pembelajaran peserta didik mengisi lembar angket dan memberikan komentar dan saran pada lembar yang telah disediakan. Berdasar pada penilaian dan masukan dari peserta didik produk diperbaiki. Hasil rekapitulasi angket pada evaluasi formatif tahap terlihat pada tabel 2.

\section{Tabel 2. Rekapitulasi Hasil Evaluasi Formatif}

\begin{tabular}{clcc}
\hline No. & Peserta Didik & Rerata Skor & Kategori \\
\hline 1 & CFK & 77,89 & Praktis \\
2 & G S H & 77,89 & Praktis \\
3 & FAC & 82,10 & Sangat Praktis \\
4 & GG & 87,37 & Sangat Praktis \\
5 & GD & 82,10 & Sangat Praktis \\
6 & JA & 81,05 & Praktis \\
7 & JES & 81,05 & Sangat Praktis \\
8 & KG & 83,16 & Sangat Praktis \\
9 & NO & 82,10 & Sangat Praktis \\
10 & SM & 90,53 & Sangat Praktis \\
\hline & Rata-Rata & $\mathbf{8 2 , 5 2 6 3}$ & \\
\hline
\end{tabular}

Analisis data hasil tes selain menggunakan KKM individu, juga menggunakan KKM klasikal. Multimedia pembelajaran PPKn dikatakan efektif apabila $85 \%$ peserta didik dapat mencapai atau melebihi KKM. Pada tabel 2, diketahui ada peningkatan signifikan dari nilai pre test ke nilai post test. Kenaikan dari nilai pre test ke post test berkisar 10 sampai dengan 60, dan peserta didik yang dapat melampaui KKM sebanyak 29 peserta didik, atau setara dengan 90,6\%.

Hal ini membuktikan bahwa multimedia menggunakan aplikasi Canva efektif terhadap hasil belajar peserta didik karena lebih dari $85 \%$ peserta didik mencapai KKM. Safitri (2018) menyatakan bahwa proses pembelajaran dikatakan tuntas secara klasikal jika $85 \%$ peserta didik di kelas mencapai KKM. Berikut merupakan tabel 3 perolehan skor pre test dan post test.

Tabel 3. Rekapitulasi Perolehan Skor Pre Test dan Post Test

\begin{tabular}{lcccccc} 
& Pre Test & Kategori & Post Test & Kategori & N-gain & Kategori \\
\hline Jumlah & 1840 & & 2605 & & 17,994086 & \\
Rerata & 57,5 & Rendah & 81,4 & Tinggi & 0,56 & Sedang \\
\hline
\end{tabular}




\section{PEMBAHASAN}

Jenis penelitian ini menggunakan Development Research penelitian pengembangan, dengan menggunakan model pengembangan Hannafin \& Peck yang telah diadaptasikan. Berdasarkan proses pengembangan yang telah dilakukan penelitian ini menghasilkan produk multimedia pada pembelajaran PPKn kelas VIII yang valid, praktis, dan efektif. pengembangan dalam memproduksi multimedia melalui tiga tahap yaitu analisis kebutuhan, desain, serta pengembangan dan implementasi. Kegiatan pada tahap analisis kebutuhan terdiri dari analisis karakteristik peserta didik, analisis lingkungan belajar, mengidentifikasi tujuan dan sasaran multimedia, merancang instrumen, serta evaluasi dan revisi.

Berdasarkan hasil wawancara dan observasi lapangan, ditemukan beberapa kendala dalam mata pelajaran PPKn di kelas, pada umumnya dianggap membosankan dan monoton, untuk itu pelajaran PPKn kurang diminati, maka sebagian besar peserta didik tidak dapat melampaui Kriteria Ketuntasan Minimal (KKM), pebelajar beranggapan pembelajaran kurang berpengaruh pada kehidupan seharihari. Sarana dan prasarana di sekolah seperti halnya komputer, laptop, proyektor, jaringan wifi sangat memadai,sehingga bisa dimanfaatkan untuk pembelajaran PPKn agar anggapan pelajaran membosankan dan monoton dapat diminimalisir serta materi menyadari pentingnya kedudukan dan fungsi Pancasila dalam kehidupan bernegara disampaikan dengan mudah, dengan demikian peserta didik dapat lebih mudah memahami materi sehingga hasil belajar peserta didik meningkat. Berdasarkan hasil observasi lapangan dari 32 peserta didik 28 diantaranya menyukai media pembelajaran audio dan visual peserta didik ternyata membutuhkan media pembelajaran yang dirancang dengan baik. Upaya yang bisa dilaksanakan dengan tujuan mendukung gaya belajar ini yaitu dengan mengembangkan multimedia pembelajaran. Berdasarkan Gumelar (2014), multimedia ialah kombinasi dari gambar, teks, video, audio, atau animasi yang bertujuan untuk dihasilkan keluaran tertentu berbentuk informasi yang menyenangkan. Maka multimedia ini bisa menjadi solusi untuk kesulitan belajar siswa terkait berdasarkan gaya belajar masing-masing peserta didik.

Tahap selanjutnya yaitu menganalisis lingkungan belajar, peserta didik telah terbiasa menggunakan komputer karena di sekolah ada pembelajaran komputer dengan kata lain mereka telah familiar dengan komputer. Didukung fasilitas SMP Xaverius 6 sangat memadai seperti tersedianya komputer, laptop, proyektor di setiap kelas, jaringan internet mampu mendukung multimedia canva. Aplikasi canva dipilih dengan pertimbangan kemampuan pendidik dalam hal tekonologi cukup bagus, dimasa ini pendidik sudah terbiasa pada penggunaan macam-macam aplikasi dalam mengajar, aplikasi canva mudah dalam pengoperasian, serta mempunyai kelebihan dimana aplikasi canva memiliki fitur yang mudah pada saat mendesain dan kompatibel dengan platform seperti Dropbox, Google Drive, dan Google Classroom sebagai alat mengajar, cara persiapkan kelas jarak jauh dengan canva untuk pendidikan (canva.com: 2020), kemudian canva juga merupakan sarana yang dapat mempermudah presentasi karena media ini dapat menampilkan teks, video, animasi, audio, gambar, grafik dan lainlain berdasarkan tampilan yang disenangi, juga sangat bagus untuk mendorong kreativitas, meningkatkan kolaborasi, dan melancarkan pembelajaran, dapat dimanfaatkan sebagai aplikasi pembuat media pembelajaran menjadi menarik serta mampu mendukung dalam peningkatan hasil belajar.

Tahap berikutnya yaitu mengidentifikasi tujuan dan sasaran multimedia. SMP Xaverius 6 menerapkan Kurikulum 2013. Materi menyadari pentingnya kedudukan dan fungsi Pancasila dalam kehidupan bernegara dipilih karena merupakan materi yang sulit dipahami oleh peserta didik. Setelah identifikasi tujuan dan sasaran multimedia kemudian instrumen penelitian disusun yang disesuaikan dengan teknik pengumpulan data yang telah disusun sebelumnya, teknik pengumpulan data tersebuat antara lain walkthrough, wawancara, angket, observasi, dan tes. Instrumen pendukung pengumpulan data yaitu lembar validasi, lembar wawancara, lembar angket, lembar observasi, dan soal yang terdiri 
atas dua puluh soal pilihan ganda. Dengan selesainya tahap analisis kebutuhan, selanjutnya dilakukan tahap evaluasi dan revisi terhadap RPP, materi, sumber materi, konten multimedia, serta instrumen penelitian.

Pada tahapan validasi terdiri dari beberapa tahap seperti tahap mengembangkan multimedia menggunakan aplikasi Canva; tahap pengujian terhadap materi, tahap desain, dan tahap media; tahap evaluasi formatif; serta uji coba lapangan. Desain pembelajaran, materi, dan media dilakukan pengujian oleh ahli untuk mendapatkan hasil validasi multimedia yang sedang dikembangkan. Perolehan nilai hasil validasi reratanya sebesar $84,2 \%$, memedomani pendapat Riduwan (2010) yang menyatakan bahwa rentang skor $81 \%$ - 100\%, maka dengan demikian perolehan hasil validasi termasuk kategori sangat aktif. Setelah ahli (Expert Review) menyatakan valid lalu evaluasi formatif atau uji coba kepada peserta didik dilaksanakan dengan tujuan untuk menghasilkan multimedia yang praktis.

Pada tahapan praktikalitas dilakukan pengujian praktikalitas kepada peserta didik (evaluasi formatif) melalui dua tahap evaluasi, peserta didik diwawancari dan diberi lembar angket. Pada tahap pertama Evaluasi formatif diujikan pada tiga orang peserta didik dengan kemampuan tinggi, sedang, dan rendah. Peserta didik yang terlibat dalam evaluasi formatif tahap kedua sebanyak sepuluh orang mereka dipilih mewakili seluruh peserta didik dengan kategori jenis kelamin, agama, suku, dan kondisi sosial ekonomi. Wawancara Evaluasi formatif tahap pertama hasilnya sebagai acuan perbaikan multimedia. Penelitian yang relevan dilakukan oleh Riduwan (2010) menyatakan bahwa skor praktikalitas dengan rentang nilai $81 \%$ - 100\% masuk dalam kategori sangat praktis, dengan demikian analisis angket evaluasi formatif tahap kedua hasilnya termasuk kategori sangat praktis, mengingat perolehan rerata sebesar $82,52 \%$. Serta saran yang diberikan oleh peserta didik saat tahap evaluasi formatif tahap kedua dijadikan sebagai acuan perbaikan.

Pada tahapan akhir yaitu penentuan efektifitas produk, dilakukan uji coba lapangan terhadap hasil belajar peserta didik. Pada tahap ini dilakukan pre test dan post test untuk mengetahui skor pebelajar sebelum dan setelah belajar menggunakan multimedia pembelajaran PPKn. Berdasarkan analisis nilai pre test dan post test diketahui bahwa nilai peserta didik mengalami peningkatan. Meningkatnya nilai tersebut menunjukkan bahwa multimedia pembelajaran PPKn dapat membantu meningkatkan pemahaman peserta didik terhadap materi menyadari pentingnya kedudukan dan fungsi Pancasila dalam kehidupan bernegara. Mengacu pada analisis data post test yang telah dilakukan terdapat 29 peserta didik atau setara 90,6 \% dapat mencapai nilai KKM, sedangkan 3 peserta didik belum mencapai KKM. Rerata hasil analisa data pre test menunjukkan 57,5 termasuk dalam kategori rendah, dan rerata nilai post test senilai 81,4 dengan kategori tinggi. Hake (1999) menyatakan bahwa jika $0,3 \leq$ $\mathrm{g} \leq 0,7$ maka N_Gain yang dihasilkan termasuk dalam kategori sedang, dari analisis diperoleh nilai rerata $\mathrm{N}$-gain yaitu 0,56 termasuk kriteria sedang. Berarti multimedia pembelajaran PPKn efektif untuk hasil belajar pebelajar. Hasil analisis data observasi pertemuan dengan menggunakan multimedia pembelajaran diperoleh rerata sebesar 69,09. Menurut Purwanto (2012) jika skor rerata observasi $65-75 \%$ maka termasuk kategori aktif. Sehingga dapat disimpulkan bahwa peserta didik aktif dalam mengikuti pembelajaran menggunakan multimedia pembelajaran PPKn.

Penelitian yang dilakukan relevan dengan penelitian yang dilakukan oleh Rahmatullah (2020), hasilnya menunjukkan bahwa peserta didik lebih mudah menguasai materi ketenagakerjaan menggunakan media pembelajaran audio visual berbasis aplikasi. Penelitian Pengembangan Multimedia Pembelajaran PPKn di Sekolah Menengah Pertama juga dilakukan oleh Rukianing (2014) dengan hasil yang sama dengan penelitian yang dilaksanakan bahwa multimedia pembelajaran interaktif pada mata pelajaran PKn meningkatkan hasil belajar PKn siswa. Penelitian yang relevan selanjutnya terkait multimedia terhadap mata pelajaran dominan teks oleh Nafi'a (2020) dan Pratama (2021) menunjukkan bahwa multimedia yang dikembangkan layak untuk diberikan kepada peserta 
didik. Selanjutnya penelitian terkini oleh Ramadhan dan Husna (2021) menjabarkan bahwa penggunaan teknologi berbasis jaringan dalam hal ini aplikasi google classroom pada pelajaran PPKn memiliki hubungan yang signifikan dengan hasil belajar dan hubungan tersebut berjenis hubungan positif.

\section{SIMPULAN}

Multimedia PPKn berbasis canva dapat menjadi salah satu variasi media pembelajaran. Multimedia berbasis canva dapat meningkatkan pemahaman siswa dengan adanya pengulangan pada materi yang diberikan. Siswa juga dapat termotivasi untuk belajar karena adanya feedback/balikan pada evaluasi yang diberikan. Siswa juga dengan mudah mengakses materi apabila dipergunakan siswa dalam belajar mandiri di rumah karena multimedia berbasis canva ini dapat diakses melalui tautan yang pendidik bagikan. Multimedia berbasis canva dapat membantu siswa dalam belajar mandiri di rumah sehingga membantu upaya pemerintah dalam mengatasi pandemi covid-19. Selain itu desain dan beberapa fitur pada multimedia berbasis canva yang dibuat menarik minat siswa dalam belajar. Dalam penilaian ahli materi dan ahli media menyatakan multimedia tutorial yang dibuat valid dan layak digunakan. Dalam uji coba lapangan yang dilakukan diperoleh hasil efektif. Selain itu menggunakan multimedia berbasis canva dalam pembelajaran PPKn dapat membantu upaya pemerintah untuk siswa belajar di rumah di tengah pandemic covid-19.

\section{DAFTAR RUJUKAN}

Agustini, R., \& Purnomo, M. E. (2020). Pengembangan Multimedia Interaktif Tenun Polos Kelas XI Kompetensi Keahlian Kriya Kreatif Batik Dan Tekstil SMKN 7 Palembang. 10(1), 33-45.

Aprianto, Muhamad, Saida Ulfa, dan Arafah Husna. 2021. "Pengembangan Multimedia Interaktif Mobile Learning Penpendidiksan Jenazah.” JKTP: Jurnal Kajian Teknologi Pendidikan 4(1): 23-32.

Bagaskoro, d. a. (2019). pengembangan media Pembelajaran video animasi model example non example muatan pelajaran ppkn kELAS III SDN Mangkang Kulon ... https:// lib.unnes.ac.id/33535/

Barrimi, M., Aalouane, R., Aarab, C., Hafidi, H., Baybay, H., Soughi, M., Tachfouti, N., Nejjari, C., Mernissi, F. Z., Rammouz, I., \& McKenzie, R. B. (2013). 済無No Title No Title. Encephale, 53(1), 59-65. http://dx.doi.org/10.1016/j.encep.2012.03.001

Hake, R. R. (1999). Analyzing change/gain score. [Online] Tersedia: http://www.physics.indiana.edu/nsdi/AnalyzingChange-Gain.pdf [Diakses 3 Januari 2020].

Junaidi, J. (2019). Peran Media Pembelajaran Dalam Proses Belajar Mengajar. Diklat Review : Jurnal manajemen pendidikan dan pelatihan, 3(1), 45-56. https://doi.org/10.35446/diklatreview.v3i1.349

Kemdikbud. (2020). Penyesuaian Kebijakan Pembelajaran di Masa. Www.Kemdikbud.Go.Id, 26. https://www.kemdikbud.go.id/main/blog/2020/08/kemendikbud-terbitkan-kurikulum-daruratpada-satuan-pendidikan-dalam-kondisi-khusus

Khasana, I. N., Parmiti, D. P., \& Sudatha, I. G. W. (2018). Pengembangan Media Monopoli Dengan Model Hannafin Dan Peck Mata Pelajaran Ips Di Sd Mutiara Singaraja. Jurnal Jurusan Teknologi Pendidikan, 6(2), 205-214.

Marlina, L. (2019). Peranan Pembelajaran Pendidikan Kewarganegaraan Siswa. 3(1), 58-70.

Muhson, A. (2010). Pengembangan Media Pembelajaran Berbasis Teknologi Informasi. Jurnal Pendidikan Akuntansi Indonesia, 8(2). https://doi.org/10.21831/jpai.v8i2.949

Nafi'a, Muhammad Zidni Ilman., Degeng, I Nyoman Sudana., Soepriyanto, Yerry. (2020). Pengembangan Multimedia Interaktif Materi Perkembangan Kemajuan Teknologi Pada Mata Pelajaran Ilmu Pengetahuan Sosial. JKTP: Jurnal Kajian Teknologi Pendidikan 
Nugroho, H. W. (2020). Peranan Mata Pelajaran PPKn Dalam Rangka Menumbuhkan Nilai Karakter Religius Siswa Kelas IV Di SDN 3 Wuryorejo Kabupaten Wonogiri Tahun Pelajaran 2017/2018. Civics Education And Social Sciense Journal (CESSJ, 1(1), 18-36.

Nurhidayah, D., Aisyah, E. S., \& Nurjannah, J. (2020). PKn dalam Kurikulum 2013. JPPHK (Jurnal Pendidikan Politik, Hukum Dan Kewarganegaraan), 10(1), 1-13.

Nurrita, T. (2018). Pengembangan Media Pembelajaran Untuk Meningkatkan Hasil Belajar Siswa. MISYKAT: Jurnal Ilmu-ilmu Al-Quran, Hadist, Syari'ah dan Tarbiyah, 3(1), 171. https://doi.org/10.33511/misykat.v3n1.171

Pratama, Nanda Kresna., dkk. (2021). "Pengembangan Multimedia Interaktif Geografi Kelas X Materi Tata Surya.” JKTP: Jurnal Kajian Teknologi Pendidikan 4(2): 119-28.

Pravasta, L., Leryan, A., Damringtyas, C. P., Priyo, M., \& Intan, B. (2018). THE USE OF CANVA APPLICATION AS AN INNOVATIVE. 190-203.

Purwanto, Ngalim. (2012). Prinsip-Prinsip dan Teknik Evaluasi Pengajaran. Bandung: PT Remaja Rosdakarya.

Rahmatullah, R., Inanna, I., \& Ampa, A. T. (2020). Media Pembelajaran Audio Visual Berbasis Aplikasi Canva. Jurnal Pendidikan Ekonomi Undiksha, 12(2), 317-327.

Ramadhan, Dhifa Putra, dan Arafah Husna. 2021. "HUBUNGAN ANTARA PENGGUNAAN GOOGLE CLASSROOM.” JKTP: Jurnal Kajian Teknologi Pendidikan 4(2): 178-87.

Reni Anita, D. B. dan R. J. (2019). Pengembangan Media Pembelajaran Pendidikan Pancasila dan Kewarganegaraan Menggunakan Program Movie Maker di Sekolah Menengah. Jurnal Inovasi Pendidikan.

Riastuti, Rahayu E., Surya Ningsih, R. I., Puji Asmaroini, A., \& Cahyono, H. (2018). Implementasi Metode Pembelajaran Discovery Learning Pada Mata Pelajaran Ppkn Untuk Membentuk Civic Skill (Studi Di Kelas Viii Smpn 1 Jenangan, Kabupaten Ponorogo). Jurnal Pancasila dan Kewarganegaraan, 3(1), 60-69. https://doi.org/10.24269/jpk.v3.n1.2018.pp60-69

Riduwan. (2010). Metode dan Teknik Menyusun Tesis. Bandung: Alfabeta.

Riyana, C. (2011). Ict Dalam Perpustakaan. Edulib, 1(1), 61-76. https://doi.org/10.17509/edulib.v1i1.1143

Rukianing, Luh Ayu., I Wayan Romi Sudhita, Luh Putu Putrini Mahadewi. 2014. Pengembangan Multimedia Pembelajaran Interaktif Pkn Dengan Model Addie Untuk Siswa Kelas VII SMP. eJournal Edutech Universitas Pendidikan Ganesha Jurusan Teknologi Pendidikan 2 (1).

Safitri, Melly, Yennita, dan Irdam Idrus. 2018. "Upaya Meningkatkan Aktivitas Dan Hasil Belajar Ipa Siswa Melalui Penerapan Model Problem Based Learning ( PBL )." jurnal Pendidikan dan Pembelajaran Biologi 2(1): 103-12.

Samsuri. (2013). Paradigma Pendidikan Kewarganegaraan Dalam Kurikulum 2013. FKIP Universitas Ahmad Dahlan, September, 1-11.

Sari, A. S., \& Wati, I. W. K. (2020). Visibility of Learning Media of a Culinary-Based Electronic Magazine in Blended Learning. Jurnal Pendidikan Teknologi dan Kejuruan, 26(1), 35-42. https://journal.uny.ac.id/index.php/jptk/article/view/28018

Sisca, R. (2017). Peran Teknologi Pendidikan dalam Mengembangkan Pendidikan Multikultural di Indonesia. 1-12. https://media.neliti.com/media/publications/220156-peran-teknologipendidikan-dalam-mengemb.pdf

Sugiyono. (2019). Metode Penelitian Kuantitatif, Kualitatif dan R\&D. Bandung: Alfabeta.

Tanjung, R. E., \& Faiza, D. (2019). Canva Sebagai Media Pembelajaran Pada Mata Pelajaran Dasar Listrik Dan Elektronika Rahma Elvira Tanjung 1), Delsina Faiza 2) 1. Jurnal Vokasional Teknik Elektronika dan Informatika, 7(2), 79-85. 
Wahono, M., \& Wardhani, N. W. (2016). Dinamika pelaksanaan Kurikulum 2013 pada tingkat sekolah menengah pertama di Kota Semarang. Jurnal Civics: Media Kajian Kewarganegaraan, 13(2), 127-136. https://doi.org/10.21831/civics.v13i2.12724

Wati, U. A. (2010). Pelaksanaan Pembelajaran yang kondusif dan efektif. Jurnal pendidkan.

Wicaksana, E. J., Atmadja, P., \& Asmira, Y. (2020). Pengembangan Poster Kesehatan Reproduksi Berbasis Pendidikan Karakter Menggunakan Canva pada Usia Remaja Sekolah di SMA. Jurnal Penelitian dan Pengkajian Ilmu Pendidikan: e-Saintika, 4(2), 160. https://doi.org/10.36312/esaintika.v4i2.215

Widiatmaka, P. (2016). Kendala Pendidikan Kewarganegaraan dalam membangun karakter peserta didik di dalam proses pembelajaran. Jurnal Civics: Media Kajian Kewarganegaraan, 13(2), 188 198. https://doi.org/10.21831/civics.v13i2.12743

Widyaningrum, H. (2016). Pentingnya Strategi Pembelajaran Inovatif Dalam Menghadapi Kreativitas Siswa Di Masa Depan. Proceedings International Seminar FoE (Faculty of Education), 1, 268 277.

Wildan. (2017). Model Pengembangan Perangkat Pembelajaran Bagi Pendidik. Society Jurnal Jurusan Pendidikan IPS Ekonomi, XVII, 41-63. https://core.ac.uk/download/pdf/266979224.pdf 